\title{
WEIGHTED ITERATED DISCRETE HARDY-TYPE INEQUALITIES
}

\author{
B. K. Omarbayeva, L.-E. Persson and A. M. Temirkhanova
}

Abstract. Necessary and sufficient conditions on functions $u$ and $\omega$ are established ensuring boundedness of a discrete Hardy-type operator from a weighted sequence space $l_{p, u}$ to a weighted sequence space for a wide range of the numerical parameters $p, u$ and $\theta$.

Mathematics subject classification (2010): 26D15, 26D20. terizations.

Keywords and phrases: Inequalities, Hardy-type operator, weights, discrete Lebesgue spaces, charac-

\section{REFERENCES}

[1] K.F. ANDERSEN AND H. HeINIG, Weighted norm inequalities for certain integral operators, SIAM J. Math. 14 (1983), 834-844.

[2] G. BenNetT, Some elementary inequalities, Quart. J. Math. Oxford Ser. 38, 2 (1987), 401-425.

[3] G. Bennett, Some elementary inequalities, III, Quart. J. Math. Oxford Ser. 42, 2 (1991), 149-174.

[4] M.Sh. Braverman And V.D. Stepanov, On the discrete Hardy inequality, Bull. London Math. Soc. 26 (1994), 283-287.

[5] V.I. Burenkov and R. Oinarov, Necessary and Sufficient conditions for boundedness of the Hardy-type operator from a weighted Lebesque space to a Morrey-type space, Math. Inequal. Appl. 16, 1 (2013), 1-19.

[6] K.G. Grosse-ERDMANn, The blocking technique, weighted mean operators and Hardy's inequality, Lecture Notes Math. 1679, Springer Verlag 1998.

[7] G.H. HARDY, Notes on some points in the integral calculus, LX. An inequality between integrals, LX. An inequality between integrals, Messenger of Math. 54 (1925), 150-156.

[8] A.Kufner, L. Maligranda And L.-E. Persson, The Hardy Inequality About its History and Some Related Results, Vydavatelsky Servis Publishing House, Pilsen, 2007.

[9] A.Kufner, L. Maligranda And L.-E. Persson, The prehistory of the Hardy inequality, Amer. Math. Monthly 113 (2006), 715-732.

[10] A. Kufner, L-E. Persson And N. SAmko, Weighted inequalities of Hardy type, Second Edition, World Scientific Publishing Co. Pte.Ltd., New Jersey, 2017.

[11] R. Oinarov, C.A. OKPOTI AND L.-E. Persson, Weighted inequalities of Hardy type for matrix operators: the case $q<p$, Math. Inequal. Appl. 10, 4 (2007), 843-861.

[12] R. Oinarov AND S.KH. ShalgYnBAEVA, Weighted additive estimate of a class of matrix operators, Izvestiya NAN RK, serial Phys.-Mat. 7, 1 (2004), 39-49. (in Russian).

[13] C.A. OK Poti, L.-E. Persson And A. Wedestig, Scales of weight characterizations for the discrete Hardy and Carleman type inequalities, In: Proc.Conf. "Function Spaces, Differential Operators and Nonlinear Analysis", FSDONA 2004 (Milovy, May 28-June 2, 2004), Math. Inst. Acad. Sci. Czech Republic, Prague 2005, 236-258.

[14] D.V. Prokhorov and V.D. Stepanov, On weighted Hardy inequalities in mixed norms, Proceedings of the Mathematical Institute. V.A. Steklova, 283 (2013), 155-170. (in Russian).

[15] A. Temirkhanova, Estimates for Discrete Hardy-type Operators in Weighted Sequence Spaces, $\mathrm{PhD}$ thesis, Department of Mathematics, Luleå University of Technology, 2015. 